\title{
Reliability and validity of the revised impact on family scale (RIOFS) in the hospital context
}

\author{
Yorschua F. Jalil ${ }^{1,2,3^{*}}$ D, Gregory S. Villarroel ${ }^{1,4,5}$, Alejandra A. Silva', Lilian S. Briceño ${ }^{1}$, Vanessa Perez Ormeño ${ }^{1}$, \\ Nicolas S. Ibáñez ${ }^{1}$, Paulina A. Méndez ${ }^{1}$, Cristina F. Canales ${ }^{1}$ and Mireya A. Méndez ${ }^{1,4}$
}

\begin{abstract}
Background: The lack of formal instruments to measure Burden in primary caregivers of Children in a hospital context is limited because mostly of published instruments are related to cancer survivors, ambulatory environment or general context for children with chronic conditions, but none of them adapted property to prolonged hospitalization context. This leaves the rising population of hospitalized chronic children's caregivers without a proper assessment. The aim of this study was to develop a version of the Revised Impact on Family Scale adapted to primary caregivers of chronic hospitalized children. A cross-sectional study with two main stages was conducted. The first one describes the linguistic and contextual adaptation process of the instrument, and the second refers to the psychometric testing and analysis.
\end{abstract}

Results: Less than 15\% of the participants expressed problems with some adapted items in the scale. Eighty-six caregivers were evaluated at Josefina Martinez Hospital, mostly female ( $34.2 \pm 11.6$ years old). Majority of participants were graduated from high school, salaried employee and mothers of the chronic child. The scale exhibits a high level of internal consistency (Cronbach's alpha 0.73), excellent intra-observer reliability (Intraclass Correlation Coefficient 0.9), acceptable empirical evaluation of content validity and low and negative construct validity (Pearson's correlation coefficient -0.23 ).

Conclusions: This adapted version of the Revised Impact on Family Scale to the hospital context is a reliable, valid, self-administered and simple instrument to implement in order to assess the burden of primary caregivers with chronic hospitalized children.

Keywords: Chronic illness, Family burden, Care givers, Impact on family scale, Children, Reliability, Validity

\section{Background}

In the last two decades, survival of severely ill children has increased due to technological advances and new health strategies changing the epidemiology of childhood diseases and guiding them towards chronicity [1-3]. However, prognosis, life expectancy, health related quality of life (HRQoL) and quality of life (QoL) can be affected [4]. Functional limitations and long-time hospitalization also can affect their family environment

\footnotetext{
*Correspondence: yjalilcontreras@gmail.com

'Department of Kinesiology and Respiratory Rehabilitation, Hospital Josefina

Martínez, Avenida Camilo Henríquez 3691, Puente Alto, Santiago, Chile

²Escuela de Kinesiología, Facultad de Ciencias de la Rehabilitación,

Universidad Andrés Bello, Santiago, Chile

Full list of author information is available at the end of the article
}

since caregivers usually bear important and multidimensional responsibilities over the time $[4,5]$. The effective management of these problems associated with caregiving is a main challenge for involved parents, affecting their physical and psychological health, becoming a threat for whole family function [6-8].

Burden and family impact measures, associated to different scenarios of the chronic child care, are key aspects to achieve a proper management of this population. Inadequate assessment of the situation and non-systematic interventions from the health care providers can leave families to struggle alone in order to manage a wide child's health issues during a hospitalization [8, 9]. Early detection of underlying problems can help to offer 
timely and appropriate health support to prevent family malfunction during child's prolonged hospitalization [9, 10]. Learn to face, for example, how the transition from a long stay hospital to the child's home can impact the family environment, which nowadays is part of their gold standard management $[4,9,11,12]$.

Sadly, instruments to measure caregiver burden in different contexts are not always available. Factors such as translation difficulties, cultural differences between populations, absence of a real family environment and context of application may explain the lack of formal instruments. For instance, different clinical scenarios of patient care, e.g. homecare, intensive care unit or a long-term rehabilitation facility, might affect the applicability of current scales mainly designed for the ambulatory context $[13,14]$. Indeed, there is few formal adapted instruments for burden assessment in an hospital context that can be compared later in other context such as home [15]. Mostly of published instruments for caregiver's burden are related to cancer survivors, local environments or general context of children with chronic conditions, but none of them adapted property to chronic hospital context $[6,9,16,17]$.

The Impact On Family Scale (IOFS) [18-20] is an instrument originally designed to assess family burden in the pediatric ambulatory care context. The initial version of it consisted in 27 items grouped in four factors (financial, familial/social, personal strain and mastery), however, a "Revised version of the IOFS" (RIOFS-Table 1) considering only 15 items has shown better psychometric properties than the original IOFS, recommending its use as a shorter, representative and more reliable single factor solution scale $[7,21]$.
Different cross-culturally adaptions of the IOFS and RIOFS have been developed, including versions in Turkey, Germany, Brazil and France [22, 23]. These adaptations have evidenced the existence of cultural and linguistic differences leading to erroneous interpretations without the formal adaptation process [24]. The performance of either IOFS or RIOFS in the hospital context remains uncertain, leaving the chronic hospitalized children's caregiver without a formal burden assessment $[7,23]$. The purpose of this study was to develop a formal version of the Revised Impact on Family Scale adapted for primary caregivers in the hospital context of chronically ill children.

\section{Methods}

Study design

We conducted a descriptive cross-sectional study for contextual and linguistic adaptation of an instrument for caregiver burden assessment. The entire process was divided in two stages: First, a five step linguistic and contextual instrument adaptation was performed [25-27]. Second, a psychometric analysis of the adapted instrument obtained in the first stage was conducted [26]..

\section{Cross-cultural linguistic and contextual adaptation}

This process considered five steps (Fig. 1):

1. Direct translation: Conceptual initial translation was made by two bilingual translators; whose native language was Spanish. The first translator knew the objectives of the study and the features which the scale intended to measure and has previous experience in technical text reduction. The second

Table 1 English version of the RIOFS

\begin{tabular}{|c|c|}
\hline 1 & Our family gives up things because of my child's illness. \\
\hline 2 & People in the neighborhood treat us specially because of my child's illness \\
\hline 3 & We see family and friends less because of the illness \\
\hline 4 & I don't have much time left over for other family members after caring for my child. \\
\hline 5 & We have little desire to go out because of my child's illness. \\
\hline 6 & Because of the illness, we are not able to travel out of the city. \\
\hline 7 & Sometimes we have to change plans about going out at the last minute because of my child's state. \\
\hline 8 & Sometimes I wonder whether my child should be treated "specially" or the same as a normal child. \\
\hline 9 & I think about not having more children because of the illness. \\
\hline 10 & Nobody understands the burden I carry. \\
\hline 11 & Traveling to the hospital is a strain on me. \\
\hline 12 & Sometimes I feel like we live on a roller coaster: in crisis when my child is acutely ill. OK when things are stable. \\
\hline 13 & It is hard to find a reliable person to take care of my child. \\
\hline 14 & I live from day to day and don't plan for the future. \\
\hline 15 & Fatigue is a problem for me because of my child's illness. \\
\hline
\end{tabular}

For each item an answer of four choices should be considered. "1. Strongly agree; 2 . Agree; 3 Disagree; 4. Strongly disagree" 


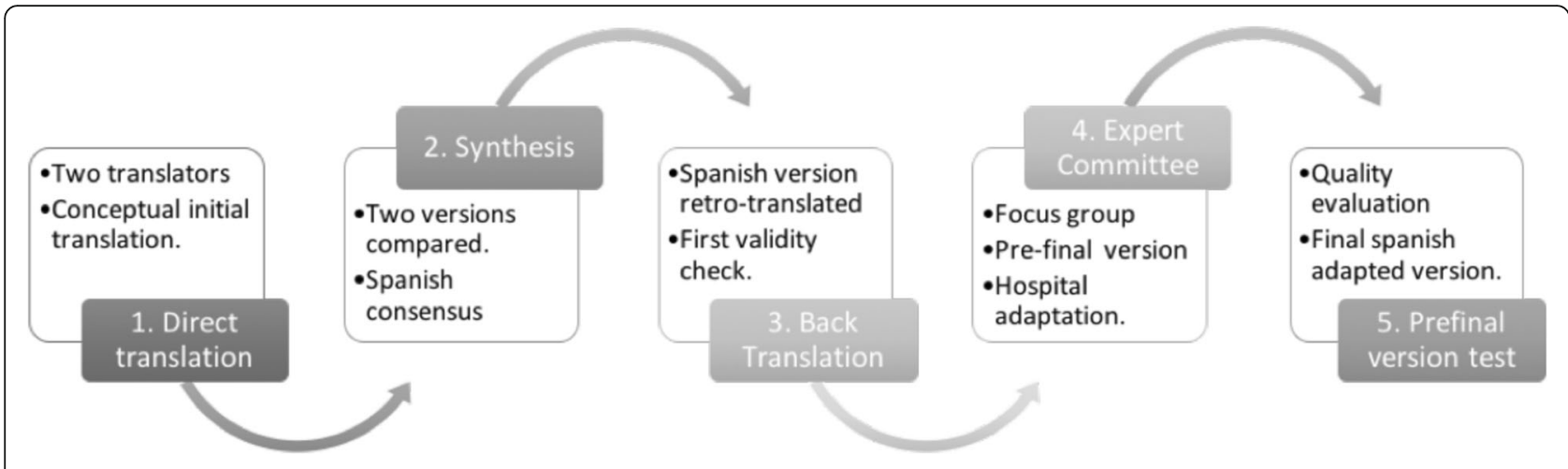

Fig. 1 Cross-cultural linguistic and contextual adaptation process

translator did not have any previous knowledge about the scale nor the study aims, offering a translation adjusted to popular language. This translator also highlights ambiguous meaning in the original questionnaire, detecting comprehension difficulties derived from the use of technical words.

2. Synthesis of the translations: The two translators, plus a recording observer, compared and synthesized both versions of the translated scale. They identified and discussed the differences between reports of the translation process. A Spanish consensus version of the RIOFS emerged from this step.

3. Back Translation: At this stage, the Spanish consensus version was translated into English by two different bilingual professional translators, whose native language was English (same as original language questionnaire). Difficult wording and conceptual errors in the back translation were highlighted in order to accomplish a first validity check.

4. Expert Committee: A multidisciplinary committee of experts (1 methodologist, 1 pneumologist specialized in chronic respiratory diseases, 1 psychologist, 1 social worker, 2 physiotherapists and 2 registered nurses) developed a single consolidated pre-final scale from the synthesis version in Spanish (after translation process, once revised and compared with the back translation). This version met the requirements to be comprehensible by a 12 years old person (evaluated by linguist and the expert committee). The committee also evaluated the applicability to the hospital context of all items, using a focus group strategy they elaborated the adapted version of the RIOFS. Every item was analyzed and adapted to the hospital context considering previous reports of translation process (provided by translators) and discussion between all committee members. This focus group was moderated by the main author, who registered the comments and prepared several reports to discriminate key information in order to achieve consensus. The ultimate result from this stage was the pre-final Spanish version of the RIOFS adapted to the hospital context prior to field test. This version, as the original RIOFS, consider 15 items with an agree-based response from 1 to 4 (Strongly agree to Strongly disagree)

5. Test of the prefinal version: This step was necessary to evaluate the quality of the pre-final consolidated version adapted to the hospital context. Thirty-six caregivers from the Hospital Josefina Martinez (HJM), Santiago, Chile; were recruited by 4 members of the research team, also part of the clinical staff, who extend them the informed consent and explain the main idea of this step. Caregivers must answered the new version and identified possible difficulties in understanding questionnaire instructions, answer options and/or items themselves. An appropriate pre-final version was considered when $15 \%$ or less of the participants, according to Ramada recommendations, reported any difficulties to answer the questionnaire [26].

\section{Psychometric testing and analysis of the adapted instrument}

Psychometrics properties, including validity and reliability, of the instrument obtained from the first stage were analyzed.

Validity analysis: Content and construct validity was considered. Content was based on an empirical evaluation by the expert committee. Construct validity was determined by its convergent variant. The application of a similar construct scale, the Family Apgar scale (currently used as part of the family impact measurement tools in the periodic evaluation at home), was performed simultaneously whit the adapted RIOFS $[19,28]$. 
Reliability analysis: Internal consistency and intra-observer reliability were evaluated. For the internal consistency, all caregivers were considered, including those ones evaluated in the pre-test stage. For the intra-observer reliability, a second measurement was necessary to the same caregivers after 2-3 weeks from the initial one. This temporary margin was established to avoid memory bias (less than 2 weeks), and to avoid that the object of measurement changed significantly between assessments (no more than 3 weeks).

\section{Participants}

Ethical approval was obtained from the South East Scientific Ethics Committee of Metropolitan Area (Santiago, Chile), and informed consent was signed by every caregiver who completed the survey prior to beginning the study.

All caregivers of inpatient children at Hospital Josefina Martinez between November 2016 and June 2017 were considered according to the following inclusion criteria: 1. To be a caregiver of a chronic inpatient child (defined according to pre-stablish criteria provided by social work team, such as visits, legal custody and care offer to the child); and 2. Level of education that allowed them to read and write (elementary school stablished by social worker and caregiver interview). Caregivers with some degree of cognitive impairment and those with a child undergoing an acute exacerbation were excluded.

Sample size was estimated according to Tinsley et al. criteria. The latter is based on variability maximization of answers, which proposes 5 to 10 subjects per item [29]. Considering that RIOFS integrates 15 items, a minimum of 75 caregivers were required (no item was dropped or added in the first stage of the scale adaptation).

\section{Data analysis}

Mean, standard deviation, frequencies and percentages were used for sample description as appropriate. Both statistical programs Stata 12.0 and SPSS 22.0 were used for the complete analysis.

\section{For the reliability study}

Cronbach's alpha coefficient was calculated as the measurement of internal consistency. Intra-observer reliability was analyzed through the intraclass correlation coefficient (ICC). Global and inter-item relation was considered using Kappa index agreement.

\section{For the validity study}

An empirical evaluation based on the interdisciplinary expert's committee debate (during the process described above) was considered for content validity. For construct validity, its "convergent" branch was used, which consisted in examining the correlation between the modified RIOFS and the Apgar Familiar Scale (FA).

\section{Results \\ Linguistic, cultural and hospital adaptation process}

The first stage result is the Spanish hospital adapted version of the RIOFS (Table 2). This final implemented version was achieved after the adjustments of some items in order to make them applicable to our context. Item number 12 presented semantic and "cultural" problems in its conception, since "roller coaster" is a common term used in the United States to express the presence of ups and downs. For our context was necessary to adapt it using the linguistic technical resource of "explicitation", which consists of adding an explanation following the desired word (a roller coaster, with highs and lows). It was necessary to understand that it is about the highs and lows in the health status of the child, requiring a more detailed description such as "Sometimes I feel as if we were living on a roller coaster (with highs and lows): in crisis when my child is unbalanced and well when he is stable". The item number 13 originally states "It is difficult to find someone you trust to take care of my child". This item did not apply to the hospital context since caregivers do not need to find someone to take care of their child (inpatient child). It was adapted to "It is difficult to place my trust in the people who take care of my child".

Pre-final version (pre-test stage) and final version were the same since only $11.1 \%$ (4 observations) of the caregivers reported some difficulties in the evaluation process. The collected comments reflected some degree of conflict in 3 specific items ( $8-10$, and). Item 8 registered 2 apprehensions, corresponding to $5.6 \%$ of the pre-test sample. This item showed that 2 answers are possible ("my child should be treated specially" or "the same as a normal child"). Item 9 corresponds to "I think about not having more children because of the illness" registered 1 apprehension. In this one it realizes that the real reason for this kind of decision was not the child illness, but family planning. Item 10 corresponding to "Nobody understands the burden I carry" also registered 1 observation, directly related to the understanding of the item, highlighting that the child in question is not the source of their sorrows, it is the disease that they suffer from.

\section{Socio-demographic characteristics}

Eighty-six caregivers (including 36 evaluated in the pretest stage) were considered for the final analysis. Among them, $60(69.8 \%)$ of the respondents were female, with a mean \pm SD age of $34.2 \pm 11.6$ years, slightly higher than men (30.4 \pm 7.4 years). Fifty caregivers $(58.1 \%)$ have completed high school, where $52.3 \%$ of them correspond to 
Table 2 Spanish hospital adapted version of the RIOFS

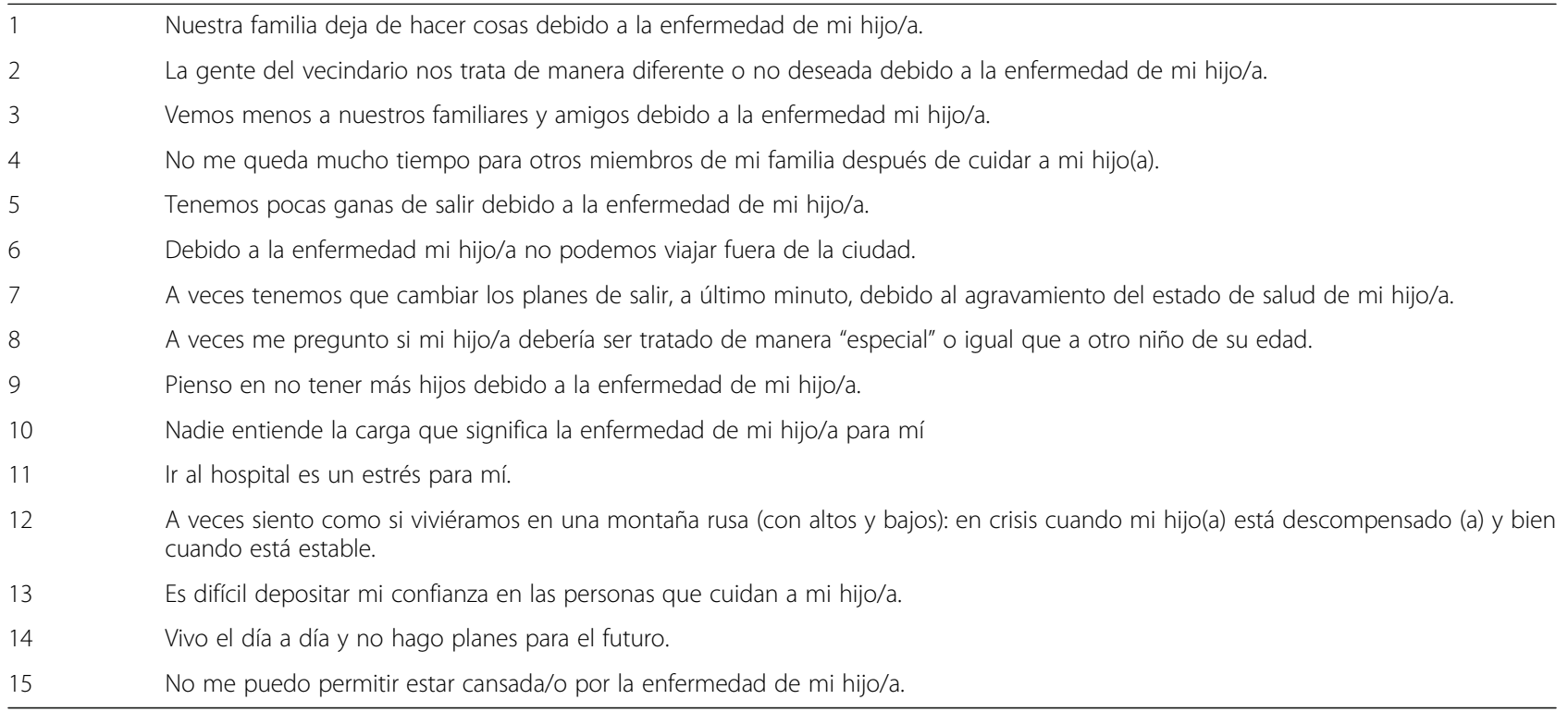

For each item an answer of four choices should be considered. "1. Muy de acuerdo; 2. De acuerdo; 3 Desacuerdo; 4. Muy en desacuerdo"

mothers of chronically inpatient children. The second proportion of caregivers corresponds to fathers (30.2\%), so parents are the main caregivers (82.5\%). Sixty-two percent declared had an employment, where $41.9 \%$ are salaried employee and the rest are freelance. The other declared occupation was housewife (29.1\%) (Fig. 2).

\section{Reliability}

Good internal consistency was found with a Cronbach's alpha coefficient value of 0.73 . Analysis of the intra-observer was differentiated into 2 parts. We used the total score of the adapted instrument, obtaining an excellent ICC (0.9). The second part considered the

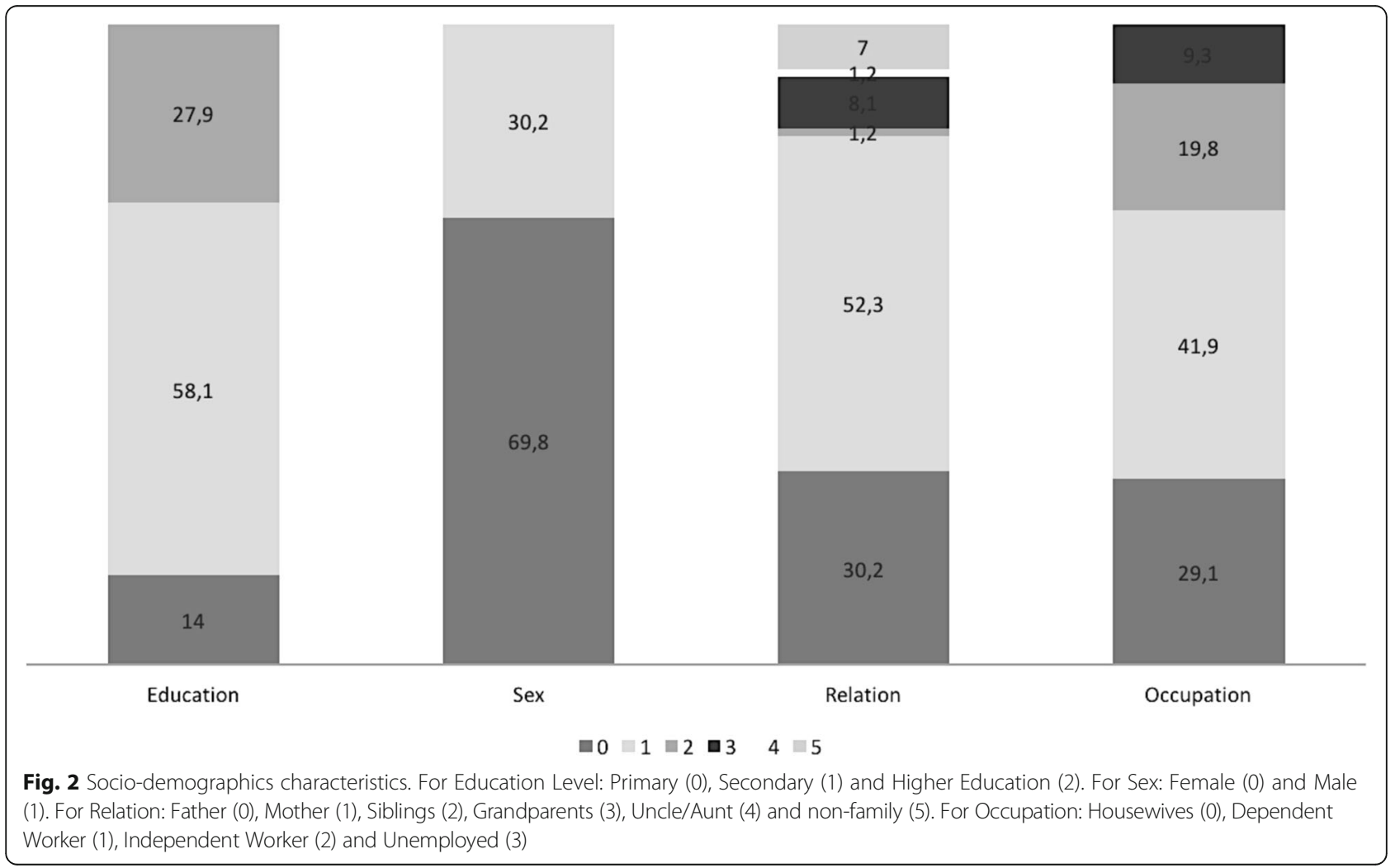


intra-observer reliability calculation between the different items ranging from 0.62 to 0.83 (Table 3).

\section{Validity}

From the clinicians and expert perspective, the committee assessed the scale as a whole, declaring it representative of "Family burden/impact" construct in hospitalized chronic children caregivers, reporting acceptable content validity. Similar assumption could be made from the caregiver's perspective, since in the pre-test stage, none of them declared not covered aspects of this domain in the questionnaire. Construct validity found a low and negative correlation with a Pearson value of -0.25 for the initial evaluation and -0.23 for the final measurement.

\section{Discussion}

The adapted version of the RIOFS in the hospital context has been presented as a simple answering tool, self-administered and adjusted to the required context. Despite reported difficulties in the pre-test stage, they were less than the expected proportion (15\%) and corresponded mostly to observations of a comprehensive nature and in a lesser proportion to interpretative difficulties, where susceptibilities inherent to the treatment of ill children prevailed. Words such as "burden" and "special treatment" seem to be key in the origin of these difficulties, however, they are caregiver-dependent and are expected in some way, considering that sensitive topics such as personal and family function are the main topics of interest.

The proposed scale exhibits "acceptable" psychometric properties of reliability and validity that would validate its application in chronic inpatient children caregiver's

Table 3 Intra-observer reliability calculation

\begin{tabular}{llll}
\hline Item & Kappa value & SD & $P$ value \\
\hline 1 & 0,734 & 0,059 & 0,000 \\
2 & 0,667 & 0,076 & 0,000 \\
3 & 0,668 & 0,066 & 0,000 \\
4 & 0,670 & 0,065 & 0,000 \\
5 & 0,696 & 0,061 & 0,000 \\
6 & 0,793 & 0,055 & 0,000 \\
7 & 0,714 & 0,063 & 0,000 \\
8 & 0,673 & 0,062 & 0,000 \\
9 & 0,621 & 0,065 & 0,000 \\
10 & 0,790 & 0,053 & 0,000 \\
11 & 0,684 & 0,067 & 0,000 \\
12 & 0,731 & 0,060 & 0,000 \\
13 & 0,643 & 0,064 & 0,000 \\
14 & 0,776 & 0,056 & 0,000 \\
15 & 0,826 & 0,049 & 0,000 \\
\hline
\end{tabular}

population. These results could be explained by the fact that RIOFS is a one-factor solution, unlike the original IOFS which exhibit poorer psychometric properties than the revised version. This does not guarantee that these properties were maintained after the translation and adaptation process. Our results suggest that they remained acceptable after this process. The internal consistency showed "acceptable" values (0.73 Cronbach's alpha), framed in the category of "good" (values $>0.7$ ), as reported by Stein et al. in other experiences with outpatient populations, exhibiting values of Cronbach's alpha of $0.89,0.87$ and 0.83 . These values do not differ from our findings [7]. The difference could be explained by two factors, the first by the context where it applies, there are no previous experiences in hospitalized children. The second determining factor is the sample size, which is similar to that used in the Turkish adaptation (85 patients), but lesser than other adaptations (over 200 patients) $[23,28,30,31]$. Although it is true that the minimum standard of patients is met to perform the psychometric adaptation, the differences in internal consistency could be explained by the greater variability associated with the smaller sample size. It should be considered that given the characteristics of the HJM, a long-term hospital (mean of 1.2 years per child admitted), with an average of only 10 admissions per year.

For intra-observer reliability, the 0.9 value found for ICC was considered excellent, very close to the 0.87 ICC reported by Boudas et al. in the French adaptation. This is the closest comparable adaptation experience of the RIOFS, since the other reports of cultural adaptation were made using the original IOFS [26]. Even if we decided to compare these last adaptations with the ICC value found in this study, we would find that they are very similar: 0.9 and 0.94 for the Brazilian and Turkish versions respectively [27].

The intra-observer reliability evaluated for each item separately through the Kappa coefficient impresses being "moderate to strong" with a range from 0.621 to 0.826 . This agrees with the intra-observer reliability for the complete scale. The items with highest reliability are those related to factors non-modifiable at short term, such as "Fatigue is a problem for me because of my child's illness" (item 15) or "no one understands the burden I carry" (item 10). Low reliability items seems to be related to daily health care, as item 13 "It is difficult to find a reliable person to take care of my child", statement that could be impacted (positively or negatively) by single action of the health team during any day..

It is necessary to mention that since it is a self-administered scale, intra-observer reliability seems an inherent property. However, different factors such as caregiver's reception to the observer initial instruction could change according to observer attitude or caregiver 
perception of it, being an important issue assess this influence through the intra-observer reliability analysis.

Regarding the convergent construct validity, that was categorized as low and negative, it seems that the FA scale points to a similar, but not equivalent construct, in contrast with the RIOFS. The FA, widely used as part of the QoL measurements by Chilean state home children care programs, shows how family members perceive the level of functioning of the family unit globally, while the RIOFS aims to determine the impact or burden that the chronic child disease generates on the family. This affects its comparability, explaining its low and negative correlation. The latter exhibits a behavior more likely expected for construct validity in its concurrent variant, which is when scales that points to different constructs are compared. Thus, if consider the application of FA as a measure of concurrent construct validity, the appropriate psychometric behavior of the proposed instrument is reinforced.

\section{Limitations}

This study has several limitations. First of them is related to the expected ability of the caregivers to write, read and to comprehend the questions in the scale. The second limitation is the sample size, which could be considered small in comparation to major studies. The study was also conducted in a single institution; however, considering the arguments in the discussion section, we don't expect that these factors alters significantly our findings.

\section{Conclusion}

In the present study the Spanish version of the RIOFS adapted to the hospital context is a reliable, valid, self-administered and simple instrument to implement in order to assess the impact/burden that diseases of chronically hospitalized children have on their caregivers and family environment. Further studies are needed in order to integrate more caregivers, allowing characterize the perceptions of this population about different clinical scenarios and interventions in health care..

\section{Abbreviations}

FA: Family Apgar; ICC: Intraclass correlation coefficient; IOFS: Impact On

Family Scale; QoL: Quality of Life; RIOFS: Revised version of the IOFS

\section{Funding}

Funding information is not applicable/ No funding was received.

\section{Availability of data and materials}

The datasets used to generate the results presented are available.

\section{Authors' contributions}

All authors worked on the development of the RIOFS, interpretation of the results and review of the manuscript. GV and YJ worked in the design of the psychometric analysis. All authors read and approved the final manuscript.

\section{Authors' information}

Y.J: PT and part of research team in Hospital Josefina Martinez, Santiago, Chile. Master of Science in Clinic Epidemiology, Universidad de la Frontera, Temuco, Chile. Academic in "Escuela de Kinesiología, Facultad de Ciencias de la Rehabilitación, Universidad Andrés Bello, Santiago, Chile". G.V: PT and part of research team in Hospital Josefina Martinez, Santiago, Chile. Coordinator of physical therapist team in governmental program "AVNI". Adjunct Instructor, Kinesiology Career, Health Sciences Department, Faculty of Medicine, Pontificia Universidad Católica de Chile, Santiago, Chile. A.S: RN in Hospital Josefina Martinez and AVNI program, Santiago, Chile. Clinical supervisor in Nurse Career, Health Sciences Department, Faculty of Medicine, Pontificia Universidad Católica de Chile, Santiago, Chile. V.P: RN in Hospital Josefina Martinez, Santiago, Chile. N.I: PT in Hospital Josefina Martinez, Santiago, Chile. L.B: RN, PALS instructor and Clinical coordinator nurse team at Hospital Josefina Martinez, Santiago, Chile. P.M: Ps for family and health team members at Hospital Josefina Martinez, Santiago, Chile. C.C: SA and coordinator hospital discharge in Hospital Josefina Martinez and AVNI program, Santiago, Chile. M.M: MD and principal director of Hospital Josefina Martinez. Clinical instructor for Clinical School of Medicine, Pontificia Universidad Católica de Chile, Santiago, Chile.

\section{Ethics approval and consent to participate}

Ethical approval was obtained from the Scientific Ethics Committee of our institution area, Prior to beginning the study the informed consent was signed by every evaluated caregiver.

Consent for publication

Included in previous section.

\section{Competing interests}

The authors declare that they have no competing interests.

\section{Publisher's Note}

Springer Nature remains neutral with regard to jurisdictional claims in published maps and institutional affiliations.

\section{Author details}

'Department of Kinesiology and Respiratory Rehabilitation, Hospital Josefina Martínez, Avenida Camilo Henríquez 3691, Puente Alto, Santiago, Chile. ${ }^{2}$ Escuela de Kinesiología, Facultad de Ciencias de la Rehabilitación, Universidad Andrés Bello, Santiago, Chile. ${ }^{3}$ Master of Science, Clinic Epidemiology, Universidad de la Frontera, Temuco, Chile. ${ }^{4}$ School of Medicine, Pontificia Universidad Católica de Chile, Santiago, Chile. ${ }^{5}$ Adjunct Instructor, Kinesiology Career, Health Sciences Department, Faculty of Medicine, Pontificia Universidad Católica de Chile, Santiago, Chile.

Received: 26 July 2018 Accepted: 25 April 2019

Published online: 14 May 2019

\section{References}

1. ATS. (2003). Statement on the Care of the Child with chronic lung disease of infancy and childhood. American Journal of Respiratory and Critical Care Medicine, 168(3), 356-396. https://doi.org/10.1164/rccm.168.3.356.

2. Stein, R. E. K., Jessop, D. J., \& Riessman, C. K. (1983). Health care services received by children with chronic illness. American Journal of Diseases of Children, 137(3), 225-230.

3. Stein, R. E. K., \& Jessop, D. J. (2003). The impact on family scale revisited: Further psychometric data. Journal of Developmental \& Behavioral Pediatrics, 24(1), 9-16. https://doi.org/10.1097/00004703-200302000-00004.

4. Pegah, P., Zahra, K., \& Nafise, M. (2017). Electronic physician ( ISSN : 20085842). Electron Physician, 9(9), 5380-5387. https://doi.org/10.14661/2015. 971-976.

5. Ortiz, L. B., Herrera, B. S., Mabel, G., \& González, C. (2013). La Carga del cuidado en cuidadores de niños con enfermedad cronica. Revista cubana de enfermeria, 29(1), 39-47.

6. Parminder, R., Maureen, O., Peter, R., et al. (2005). The health and well-being of caregivers of children with cerebral palsy. Pediatrics, 115(6). https://doi. org/10.1542/peds.2004-1689.

7. Salinas, P., Farias, A., González, X., \& Claudia, R. (2008). Calidad de vida relacionada en salud : Concepto y evaluación en pacientes con ventilación mecánica no invasiva. Neumología Pediátrica, 3, 34-39. 
8. Barlow, J. H., \& Ellard, D. R. (2006). The psychosocial well-being of children with chronic disease, their parents and siblings: An overview of the research evidence base. Child: Care, Health and Development, 32(1), 19-31. https://doi. org/10.1111/j.1365-2214.2006.00591.x.

9. Lyu, Q. Y., Kong, S. K. F., Wong, F. K. Y., \& You, L. M. (2015). Validation of hospitalization impact scale among families with children hospitalized for cancer treatment. Journal of Advanced Nursing, 71(8), 1958-1969. https://doi. org/10.1111/jan.12670.

10. Wittenberg, E., Saada, A., \& Prosser, L. A. (2012). How illness affects family members: a qualitative interview survey. NIH Public Access, 100(2), 130-134 https://doi.org/10.1016/j.pestbp.2011.02.012.Investigations.

11. Amin, R., Sayal, P., Syed, F., Chaves, A., Moraes, T. J., \& Maclusky, I. (2013). Pediatric long-term home mechanical ventilation : Twenty years of followup from one Canadian center. Pediatric Pulmonology, 1-9. https://doi.org/10. 1002/ppul.22868.

12. Vega-briceño, L., Contreras, I., Prado, F., Méndez, M., \& Sánchez, I. (2004). Hospital Josefina Martínez: Una breve reseña histórica (pp. 3-5).

13. Eiser, C., \& Morse, R. (2001). The measurement of quality of life in children: Past and future perspectives. Journal of Developmental \& Behavioral Pediatrics, 22(4), 248-256.

14. Janse, A. J., Sinnema, G., Uiterwaal, C., Kimpen, J., \& Gemke, R. (2005). Quality of life in chronic illness: Perceptions of parents and paediatricians. Archives of Disease in Childhood, 90, 486-492. https://doi.org/10.1136/adc.2004. 051722.

15. Peterson-Carmichael, S. L., \& Cheifetz, I. M. (2012). The chronically critically ill patient: Pediatric considerations. Respiratory Care, 57(6), 993-1003. https:// doi.org/10.4187/respcare.01738.

16. Toledano-Toledano, F., \& Domínguez-Guedea, M. T. (2019). Psychosocial factors related with caregiver burden among families of children with chronic conditions. BioPsychoSocial medicine, 13(1), 1-9. https://doi.org/10. 1186/s13030-019-0147-2.

17. Yaǧci-Küpeli, B., Akyüz, C., Küpeli, S., \& Büyükpamukçu, M. (2012). Healthrelated quality of life in pediatric cancer survivors: A multifactorial assessment including parental factors. Journal of Pediatric Hematology/ Oncology, 34(3), 194-199. https://doi.org/10.1097/MPH.0b013e3182467f5f.

18. Vélez, C. M., Iván, H., \& García, G. (2012). Medición de la calidad de vida en niños Quality of Life. IATREIA, 25(3), 240-249.

19. Williams, A. R., Piamjariyakul, U., Williams, P. D., Bruggeman, S. K., \& Cabanela, R. L. (2006). Validity of the revised impact on family (IOF) scale. The Journal of Pediatrics, 149(2), 257-261. https://doi.org/10.1016/j.jpeds.2006.04.003.

20. Barbosa, T. D. S., \& Gavião, M. B. D. (2009). Evaluation of the family impact scale for use in Brazil. Journal of Applied Oral Science, 17(5), 397-403. https:// doi.org/10.1590/S1678-77572009000500009.

21. Laufersweiler-Plass, C., Rudnik-Schöneborn, S., Zerres, K., Backes, M., Lehmkuhl, G., \& Gontard a, v. (2003). Behavioural problems in children and adolescents with spinal muscular atrophy and their siblings. Developmental Medicine and Child Neurology, 45, 44-49. https://doi.org/10.1017/ S0012162203000082

22. Bek, N., Simsek, I. E., Erel, S., Yakut, Y., \& Uygur, F. (2009). Turkish version of impact on family scale: a study of reliability and validity. Health and Quality of Life Outcomes, 7, 1-7. https://doi.org/10.1186/1477-7525-7-4.

23. Paiva, R., \& Navarro, S. (2013). Programa de Asistencia Ventilatoria No Invasiva (AVNI) en APS. Norma tecnica. Ministerio de Salud:Subsecretaria de redes asistenciales, Division de atención primaria de Chile.

24. Prado, F., \& Salinas, P. (2011). Asistencia ventilatoria no invasiva domiciliaria en niños : impacto inicial de un programa nacional en Chile. Revista Chilena de Pediatría, 82(4), 289-299.

25. Guillemin, F., \& Bombardier, C. (1993). Cross-cultural adaptation of healthrelated quality of life measures: literature review and proposed guidelines. J Clin Epidemiol, 46(12), 1417-1432.

26. Ramada-Rodilla, J. M., Serra-Pujadas, C., \& Delclós-Clanchet, G. L. (2013) Adaptación cultural y validación de cuestionarios de salud: Revisión y recomendaciones metodológicas. Salud pública de México, 55(1), 57-66. https://doi.org/10.1590/S0036-36342013000100009.

27. Beaton, D. E., Bombardier, C., Guillemin, F., \& Ferraz, M. B. (2000). Guidelines for the process of cross-cultural adaptation of self-report measures. Spine (Phila Pa 1976), 25(24), 3186-3191. https://doi.org/10.1097/00007632200012150-00014

28. Ravens-sieberer U, Morfeld M, Stein REK, Jessop DJ, Bullinger M. (2001). The testing and validation of the German version of the impact on family scale in families with children with disabilities Familien-Belastungs-Frage-bogen (FaBel-Fragebogen). Psychother Psychosom med Psychol, 24, 384-393.

29. Tinsley, H. E. A., \& Tinsley, D. J. (1987). Uses of factor analysis in counseling psychology research. Journal of Counseling Psychology, 34, 414-424.

30. Bullinger, M., Schmidt, S., \& Petersen, C. (2002). Group THED. Assessing quality of life of children with chronic health conditions and disabilities: a European approach. International Journal of Rehabilitation Research, 25, 197206

31. Stein, R. E., \& Jessop, D. J. (1989). Measuring health variables among Hispanic and non-Hispanic children with chronic conditions. Public Health Rep, 104(4), 377-384.

\section{Submit your manuscript to a SpringerOpen ${ }^{\circ}$ journal and benefit from:}

- Convenient online submission

- Rigorous peer review

- Open access: articles freely available online

- High visibility within the field

- Retaining the copyright to your article

Submit your next manuscript at $\boldsymbol{\nabla}$ springeropen.com 